\title{
Anartria Pura: Estudo de Dois Casos
}

\author{
André Roch Lecours \\ Universidade de Montreal, Canadá \\ Maria Alice de Mattos Pimenta Parente ${ }^{1}$ \\ Adriana Vélez. Feijó \\ Alberto Maia \\ Universidade Federal do Rio Grande do Sul
}

\begin{abstract}
Resumo
O marco do nascimento da neurolingüística é considerado a publicação do livro A síndrome de Desintegração Fonética, em 1939, que teve como autores: um neurologista, um psicólogo e uma lingüista. Dez anos mais tarde foi publicado, pela mesma equipe de pesquisadores franceses, o distúrbio de fala do paciente portador de anartria pura. No presente artigo, situaremos as polêmicas históricas a respeito de um distúrbio seletivo de fala de origem telencefálica, apresentaremos o primeiro caso descrito, acompanhado da descrição anátomo-patológica do cérebro que estivera guardado em formol por 20 anos e, realizada por um de nós (ARL), e por fim, apresentaremos um caso brasileiro, cujas imagens tomográficas de seu cérebro e espectográficas de sua fala e voz confirmam o trabalho pioneiro de Alajouanine, Pichot e Durant.

Palavras-chave: Anartria; distúrbios de fala; e lesões cerebrais.
\end{abstract}

Pure Anartria: Study of Two Cases

\begin{abstract}
The mark of birth of neuro-linguistics is considered the publication of the book The Syndrome of Phonetic Disintegration, in 1939, that had as authors: a neurologist, a psychologist and a linguistics. Ten years later the same team of French researchers published about, the disturbance of speech of the patient carrier of pure Anartria. In the present article, we will place the historical polemics regarding a selective disturbance of speech of telencephalic origin and present the first described case, accompanied by the anatomic-pathological description of the brain that had been kept in formol by 20 years accomplished by one of us (ARL). Finally, we will present a Brazilian case, with tomographic images of its brain and spectrographic evaluation of its speech and voice that confirm the pioneer work of Alajouanine, Pichot and Durant.

Keywords: Anartria; speech disturbances, cerebral lesions
\end{abstract}

O marco da participação de psicólogos nos estudos de pacientes portadores de distúrbios lingüísticos decorrentes de lesão cerebral foi a publicação, em 1939, de um livro, que contou como autores um neurologista, Theophile Alajouanine, um psicólogo, André Ombredane e uma lingüista, Marguerite Durant. Dois desses autores, juntamente com um neuropsiquiatra, descrevem, dez anos mais tarde, um paciente com um de distúrbio lingüístico que envolvia apenas a produção oral sem afetar a compreensão, a leitura ou a escrita (Alajouanine, Pichot \& Durant, 1949). Esse paciente não apresentava lesões de tronco cerebral, responsáveis por diferentes quadros disártricos e nem acentuadas dificuldades de movimento

\footnotetext{
1 Endereço para correspondência: Instituto de Psicologia, UFRGS, Rua Ramiro Barcelos, 2600, 90035-003, Porto Alegre, RS. Fone: (51) 33165066. E-mail:malicemp@zaz.com.br.
}

orofacial. Esta possibilidade de dificuldades exclusivas de produção oral foi o foco de polêmica bastante intensa nos primórdios da afasiologia e retoma a distinção conceitual entre fala e linguagem, apontada pelo fundador da lingüística, Saussure. Para Saussure (1916/1955), a linguagem corresponde a um sistema de regras e relações entre signos construídos arbitrariamente, enquanto que a fala corresponde à emissão individual da linguagem. Jakobson (1953/1973) acrescenta que "falar implica a seleção de certas entidades lingüísticas e sua combinação em unidades lingüísticas de mais alto grau de complexidade." (p.37) A neurolingüística tem mostrado que a distinção desses dois níveis lingüísticos não é apenas teórica, mas tem substratos orgânicos, importância diagnóstica e pode determinar diferentes enfoques terapêuticos.

A existência de uma desintegração fonética foi reconhecida desde cedo na história da afasiologia. Em 
1843, Lordat denominava essa síndrome "alalia por assinergia verbal". Um pouco mais tarde, na mesma época em que Broca (1861) descrevia o famoso caso Leborgne, portador de uma afasia motora e marco inicial da afasiologia, Baillarger (1865/1890) descrevia a desintegração fonética, classificando-a entre um dos quadros clínicos afásicos e denominando-a "afasia simples". Para Baillarger era inadequada a interpretação que fazia Broca de um distúrbio em uma etapa motora da fala, uma amnésia específica da propriocepção dos movimentos do aparelho fonoarticulatório. Ao se referir à preservação de um certo nível de linguagem emotiva e/ou automática, Baillarger sugeriu que existe um distúrbio específico da capacidade de produzir voluntariamente a linguagem falada. Em nosso ponto de vista, seu repudio ao papel da memória proprioceptiva (inconsciente) é evidentemente errôneo, mas sua análise opondo a produção automática e voluntária é compatível à observação clínica e ao conceito de "dissociação automático-voluntário" que persiste até hoje desde Baillarger (1965/1890) e Jackson (1873/1931).

Um pouco mais tarde, esse distúrbio restrito à fala iria gerar discussões teóricas. A maior parte delas foi realizada na França, sendo a mais significativa a oposição entre Jules Degerine e Pierre Marie, por motivos outros que a própria anartria: os dois disputaram, em 1909, a cadeira de Charcot, sendo afasia, a questão sorteada para a prova de desempenho didático.

Para Marie (1906/1926a e b), o distúrbio fonético, um termo ainda inexistente na época, não pertencia ao domínio da afasia e deveria ter um outro nome. Ele sugeriu chamá-lo de "anartria". Segundo o autor, esse quadro é específico da emissão oral, sem outra alteração e, portanto, sem afasia. As emissões do paciente são distorcidas e incompreensíveis, o que torna possível confundir a anartria com a afasia de Broca. Entretanto, em oposição aos afásicos, os anártricos entendem perfeitamente o que lhes é dito, incluindo frases complexas e, além disso, podem ler e escrever.

Pierre Marie mantinha, entretanto, que a verdadeira afasia não se caracteriza pela ausência da elocução, mas por um distúrbio da compreensão, ou seja, um tipo particular de distúrbio intelectual e por anomalias na leitura e na escrita. Essas considerações, assim como sua rivalidade contra Dejerine, levaram-no a formular a famosa equação - a lei de Pierre Marie — sobre a natureza essencialmente diferente entre anartria e afasia (Marie, 1906/1926d):

"Afasia de Broca = Afasia de Wernicke + Anartria."

Pierre Marie também tinha suas idéias quanto às localizações lesionais da anartria e da afasia. Ele atribuía à primeira um distúrbio em diferentes componentes cerebrais, que mais tarde receberam o nome "quadrilátero de Pierre Marie": (1) proximidades do núcleo lenticular, isto é, o joelho da cápsula interna; (2) parte da cápsula externa; e assim como (3) possibilidade de uma lesão na zona do núcleo lenticular do lado direito.

Dejerine $(1907,1914)$ e Marie (1906/1926a) estavam de acordo quanto às manifestações clínicas de um distúrbio articulatório isolado ou quase isolado. Entretanto, Dejerine acreditava que esse quadro clínico era um componente da afasia propriamente dita. Ele o denominava "afasia motora pura" e mantinha que o distúrbio articulatório da afasia motora subcortical era o mesmo que o da cortical (afasia de Broca). Portanto, ele rejeitava a "lei" de seu adversário: segundo Dejerine, a afasia de Broca não era uma associação entre afasia de Wernicke e anartria. Além disso, Dejerine não aceitava a definição de Marie sobre a afasia, na qual tanto a afasia de Broca como a de Wernicke eram consideradas deterioraçoes intelectuais. Sabe-se, atualmente, que a afasia pode se restringir à linguagem, se a lesão assim permitir, mas também pode incluir distúrbios cognitivos, se o dano for mais extenso.

Dejerine (1914) também insistia no fato da afasia motora pura poder se manifestar após uma evolução favorável (rápida ou lenta) de uma afasia de Broca e, por vezes, após uma afasia “total". Nesse caso, ele tinha razão, a evolução a partir de uma afasia global não é freqüente, mas ocasional. A opinião de Dejerine (1914) quanto ao local da lesão responsável pela afasia motora pura e a de Marie (1906/1926c) quanto ao local da falha relacionada à anartria eram aparentemente muito diferentes. Em seus primeiros escritos, Dejerine e Dejerine-Klumpke (1901) mantiveram, em termos que parecem inquestionáveis, que a lesão não atinge a área de Broca, mas as fibras subcorticais que chegam ou saem dessa área; ou seja, as fibras de associação que conectam a área de Broca ao opérculo rolândico. Outras observações anatomoclínicas, realizadas mais tarde, fizeram com que Dejerine adotasse uma concepção menos localizatória. Ele postulou, em 1914, a possibilidade de lesões subcorticais além das corticais. Mesmo mais tarde, continuou a afirmar que não existe nenhuma razão em crer que uma lesão no núcleo lenticular possa ser a causa de um distúrbio articulatório.

Assim como Lordat, 50 anos antes, Freud (1953/ 1891) prestes a criar a psicanálise, interessou-se aos aspectos lingüísticos das afasias. Lendo cada um desses dois autores, observa-se que Lordat (1843) interessou-se mais pela fonética do que Freud. De fato, até as primeiras décadas do século XX, a grande maioria dos indivíduos 
que fazia pesquisas sobre afasia centralizava seus trabalhos com maior ênfase nas localizações das lesões em seus aspectos lingüísticos. Este fato, logo seria mudado.

Em 1939, pela primeira vez, um livro sobre a afasia de Broca é publicado com uma descrição lingüística bastante precisa sobre falhas na manifestação fonética decorrente de lesões cerebrais. Como já referido, os autores são Théophile Alajouanine (neurologista), André Ombredane (psicólogo) e Marguerite Durand (lingüista). Esta publicação - intitulada $A$ Sindrome de Desintegração Fonética na Afasia - marca, em nossa opinião, o início da Neurolingǘstica. Passa-se, então, dos termos "aphasia motora pura" e "anartria pura" para "desintegração fonética". Dez anos mais tarde, Alajouanine e colaboradores (1949) publicaram, na revista Encéphale, o primeiro caso minuciosamente observado, quanto ao aspecto lingüístico, de uma "desintegração fonética pura".

Nesse artigo faremos dois estudos de casos com anartria pura. O primeiro é o paciente histórico, descrito por Alajouanine e colaboradores (1949), cujo estudo anátomo-patológico foi realizado por um de nós (ARL), que nos anos sessenta, encontrou, ao acaso, o cérebro desse paciente em um vidro de formol, no serviço de neuropatologia da Salpêtrière (Lecours \& Lhermitte, 1976). O segundo paciente foi examinado recentemente, no Brasil, pelos dois outros autores. A utilização de tecnologia mais avançada possibilitou um estudo espectográfico e tomográfico confirmando as observações clínicas minuciosas e o estudo anatomopatológico realizados no primeiro paciente. $\mathrm{O}$ objetivo do estudo desses dois pacientes é ilustrar a dissociação entre fala e linguagem e entre a estrutura fonética e as demais estruturas da linguagem, assim como, mostrar que a análise fonoarticulatória adequada tem uma correspondência com os padrões acústicos produzidos, apesar dos diferentes níveis de análise.

\section{Primeiro Caso}

\section{Dados Pessoais e Histórico do Incidente Neurológico}

Sr. Delfrique nasceu na França. Sua uma mãe era inglesa e seu pai, francês. Ambos falavam corretamente as duas línguas, mas o inglês era o idioma das trocas lingüísticas no contexto familiar. De fato, os filhos falavam melhor $o$ inglês do que o francês até os quatro anos. Os conhecimentos da língua francesa eram rudimentares até a entrada no ensino primário, dois anos mais tarde, onde rapidamente desenvolveu essa língua. Ele obteve, com 16 anos, um diploma que certificava o domínio perfeito do francês, tanto oral como escrito. Era considerado superior à média na escrita e foi aconselhado a tornar-se professor de escola primária na França, mas dedicou-se ao comércio. Fora algumas viagens, passou sua vida em seu país de origem onde seu trabalho o obrigava a utilizar as duas línguas que ele conhecia. Como seus parentes, era destro.

Em 10 de dezembro de 1947, com 63 anos de idade, Sr. Delfrique foi admitido no serviço de cardiologia do Hospital Lariboisière, em Paris, para o tratamento de episódios de taquicardia paroxística, há muito tempo manifestado. Dois dias após a hospitalização, o paciente sofreu um enfarte cerebral, sem perda de consciência, quando andava pelo terreno do hospital. O exame imediato revelou a presença de uma hemiplegia direita e de uma hipoestesia do mesmo lado. Sua fala ficou reduzida a um sussurro indiferenciado. Entretanto, a compreensão da linguagem dos outros, tanto quando falavam inglês como francês, era normal. Foi-lhe dado o diagnóstico de afasia de Broca.

No dia seguinte, o paciente já podia mover seu braço e sua perna direita e a hipoestesia tinha melhorado consideravelmente. No início de janeiro seguinte, ele andava normalmente. Seu distúrbio de fala, entretanto, continuava severo, mas uma recuperação rápida iniciouse após um mês: Sr. Delfrique recomeçou a falar de maneira perceptível, mas seu discurso se produzia de forma lenta, escandida e disártrica. O paciente foi transferido ao hospital La Salpêtrière, onde escreveu ao seu médico, com sua mão direita, um relato sobre sua recuperação parcial:

"Doutor, eu quero explicar-lhe porque eu silabo. Num estado normal, o pensamento se exprime pela palavra, automaticamente, não nos preocupamos ou nos preocupamos muito pouco com a articulação, pela força do hábito, ela se torna "maquinal". Há quatro semanas atrás, tudo que vinha em minha boca quando eu queria dizer uma palavra, saia um ronco. Um dia, eu consegui pronunciar "a", “i”, depois, “a”, “e”, “i”, “o”, “u”, nos dias seguintes, eu consegui algumas sílabas e palavras que começavam por vogais. Só há uns dez dias é que consegui dizer "sim". Desde que eu estou aqui, mal consegui vencer os “"j", "g", "l”. Fazem três dias que eu consegui dizer o nome de meu filho "Jean", eu não podia dizer "le", "la", "les" (em português, o, a, os). Eu preciso silabar porque a articulação é preguiçosa. Ela não é mais automática, mas precisa ser comandada. Eu preciso pensar na palavra que eu quero dizer e na sua forma de dizer, de articular. Se eu quero dizer "bonjour" (bom dia), o hábito não intervém, não é mais automático, se eu não prestar atenção eu vou dizer "boso". Se eu disser "le", "la" sem prestar atenção, eu vou dizer "de", "da". Por isso é preciso que eu articule cada vogal, cada consoante, enfim, cada sílaba (...) Estando morto o motor, o mecanismo que o fazia funcionar ficou bloqueado".

O exame neurológico, realizado no dia de sua chegada, mostrou uma perda sensoriomotora mínima do lado 
direito, incluindo na face (mas com reflexos osteotendinosos exacerbados e um sinal de Babinski do mesmo lado). Não se observava nenhuma evidência de apraxia bucofacial nem de distúrbios outros que a fala. Uma semana mais tarde, a hipoestesia não era mais observada.

\section{Avaliação Neuropsicológica e Neurolingüística}

Avaliação Neuropsicológica: Em 1948 e 1949, Sr. Delfrique foi submetido a uma impressionante bateria de diversos testes perceptivo-motores e psicométricos. Os resultados dessas avaliações encontravam-se dentro da normalidade.

Expressão Escrita: Em contraste com a perturbação ártrica que deformava a fala de Sr. Delfrique, não haviam falhas importantes na escrita espontânea. O grafismo era normal tanto em cópia como em ditado (e sob soletração, considerando-se a desintegração fonética). Mesmo com boa fluência de escrita de texto, o tempo levado na redação era longo, devido ao distúrbio motor que afetava a mão direita. Não se observavam falhas de morfologia ou semântica. As trocas formais e os erros de sintaxe eram raros, com ocorrência semelhante à de indivíduos sem lesão. Entretanto, de forma geral, sua escrita parecia normal, apesar do paciente queixar-se de perda de fluência na escrita, quando comparava a sua habilidade anterior à doença.

Compreensão: A compreensão da linguagem oral e escrita era normal e assim continuou durante a evolução do quadro. Ela foi avaliada várias vezes com estímulos lingüísticos, por vezes bastante complexos.

Expressão Oral: A melhora espontânea e a obtida pela reabilitação fonoaudiológica nos meses seguintes não foi tão rápida quanto a das quatro primeiras semanas após o acidente vascular. A fluência da fala melhorou lentamente. Neste ponto de estabilização, ocorreu uma dissociação entre a sintaxe e a semântica lexical na conversação, bastante sofisticada, e de outro lado, um grande distúrbio articulatório.

A fala era silabada, hipertônica, às vezes explosiva, com anomalias evidentes de ritmo e uma ausência quase total de prosódia. As hesitações eram freqüentes, principalmente no inicio das palavras. Elas podem ser observadas no comentário do paciente sobre sua vida profissional, se for lido de forma silabada e exagerandose a amplitude dos movimentos bucofaciais:

“ $[\mathrm{m}] \ldots[\mathrm{mOm}] \ldots$ No menmento, eu $[\mathrm{ES}] \ldots[\mathrm{ES}] .$. eu estou $\left[\mathrm{r}^{\prime}\right] \ldots$ [r']...representando os vinhos. Não é, não é meu trabalho normal..... Mas mas eu [er] eu era representante de

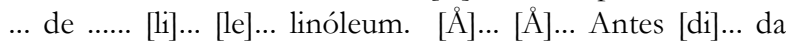
guerra, eu era agente de uma $[\mathrm{u}] \ldots[\mathrm{u}] \ldots$ usina de... uma [pa]... [pafi]... [fabik]... de linóleo e [twa] gracha."
A leitura em voz alta e a repetição seriam normais se não fossem as numerosas aproximações e distorções fonéticas. O distúrbio articulatório era perceptível tanto em inglês como em francês. Todos concordavam - Sr. Delfrique, sua familia, os profissionais da Salpêtrière, inclusive o lingüísta - que este distúrbio era mais evidente em francês, uma dissociação publicada por Alajouanine e colaboradores (1949).

\section{Avaliação Fonético-fonológica}

Uma avaliação fonética surpreendentemente sofisticada para a época foi realizada pela Senhora Durand, tanto em língua francesa como inglesa. Suas conclusões para o francês foram as seguintes:

- A duração de emissão dos fonemas era duas vezes e meio mais longa do que a dos sujeitos do grupo controle.

- As consoantes sonoras eram freqüentemente emitidas com um ensurdecimento completo ou parcial.

- Os fonemas nasais apresentavam uma falha total ou parcial de nasalização.

- A articulação das oclusivas era anormalmente forte e as fricativas podiam ser transformadas, aproximandose à oclusiva correspondente. Entretanto, a transformação das fricativas em africadas, observada em outros casos, não era perceptível nesse paciente.

- As laterais também eram transformadas em uma oclusiva próxima. A articulação do [r] era geralmente muito forte.

- Devido à instabilidade na abertura, e portanto do local de articulação, certas vogais se transformavam em "pseudoditongos" e às vezes, "pseudopolitongos".

- As vogais iniciais de certos estímulos eram habitualmente precedidas por uma consoante inserida, freqüentemente, uma consoante glotal.

- As epênteses (acréscimo de uma vogal entre duas consoantes) não eram raras.

- Apesar de menos freqüentes, outros tipos de erros eram ocasionalmente observados, como por exemplo, a substituição de um som por assimilação retrógrada, a duplicação de outro som relacionado a um fonema. Conseqüentemente, pode-se supor que o paciente realizava, "parafasias fonêmicas".

Os fenômenos descritos acima eram bem menos perceptíveis em inglês.

Estudo anátomo-patológico (Lecours \& Lhermitte, 1976): A observação da superfície do cérebro detectou uma lesão antiga que destruía a metade inferior da circunvolução frontal ascendente esquerda tocando a parte caudal da segunda circunvolução frontal deste lado. A área de Broca não foi alcançada na superfície cortical e a 
lesão se limitava, nesta perspectiva, à parte baixa do córtex motor primário.

As secções coronais, com a coloração realizada pelo método de Loyez, permitiram notar que além de uma pequena lesão no fundo do sulco singular esquerdo (destruindo uma superfície cortical muito limitada e fibras associativas curtas subjacentes), as secções que cortavam a área de Broca não mostraram evidências de dano. $O$ exame microscópico confirmou que o pé e o joelho da terceira circunvolução frontal estavam intatos. $\mathrm{O}$ infarto destruía alguns milímetros do córtex e do subcortéx caudal da segunda circunvolução frontal. Uma secção através do frontal ascendente permitiu verificar que a metade inferior dessa estrutura estava com necrose e que a lesão comprometia as fibras em «U» em direção à terceira e à quarta circunvolução frontal, assim como, em direção ao lobo parietal ascendente. A parte dorsorrostral do córtex insular foi destruída. A lesão não tocava nem a cápsula interna nem outras estruturas profundas, como os núcleos caudado e lenticular. As seções centralizadas na metade anterior e posterior da primeira circunvolução mostraram alguns danos corticais muito restritos na superfície do ínsula. Essa era a parte mais posterior da lesão. A primeira circunvolução temporal, incluindo o planun temporal incluído, e as circunvoluções supramarginais e angulares estavam intactas.

Evolução: no Centro de Linguagem do Hospital Salpêtrière, onde Alajouanine estava freqüentemente presente, Sr. Delfrique teve o privilégio de ter uma terapia intensiva da fala. $\mathrm{O}$ paciente foi seguido no hospital Salpêtrière até 1952. Embora sua fala fosse um pouco mais rápida, não foi notada uma mudança evidente em suas falhas articulatórias. As avaliações finais mostraram ligeiras dificuldades de memória. O paciente morreu um ano depois devido a um enfarte cardíaco.

\section{Segundo Caso}

\section{Dados Pessoais e Histórico do Incidente Neurológico}

O paciente RA, do sexo masculino, nasceu no Brasil, de família italiana, mas desde criança falava apenas o português. Fez curso universitário e dirigia, com muito sucesso, uma firma de consultoria econômica. Tinha uma situação econômica confortável e um bom nível cultural. Era casado, com uma filha também casada e, como seus antecedentes, era destro.

Aos 55 anos, quando guiava, seu carro parou numa sinaleira e enquanto aguardava a mudança para o sinal verde, começou a passar mal. Um rapaz, que olhava pela janela de um ônibus percebeu suas dificuldades, desceu

Psicologia: Reflexão e Crítica, 2001, 14(2), pp. 367-377 do ônibus e o levou a um hospital. Foi atendido imediatamente e diagnosticado um evento vascular encefálico (EVE) hemorrágico. Nos primeiros dias, não conseguia andar e seu lado direito, principalmente o braço, ficara paralisado. Também não emitia nenhum som. Nunca perdera a consciência, não apresentou dificuldades visuais e sempre reconheceu seus familiares, inclusive sua mulher que chegou uma hora depois no hospital. Apenas no primeiro dia teve dificuldades de deglutição com líquidos $\mathrm{e}$, durante a primeira semana, engasgava-se com alimentos sólidos. Ficou uma semana na CTI devido a dificuldades de respiração e depois mais quinze dias hospitalizado. Nesse período, fez fisioterapia e terapia de fala, sendo diagnosticada uma afasia de Broca.

Quando voltou para casa, ainda apresentava hemiparesia de predomínio braquiofacial, sem dificuldades sensoriais. Conseguia fazer sons, mas não formar palavras. Seus familiares ensinaram a palavra "mão", e começou a apresentar perseverações, dizendo para tudo "mão".

\section{Avaliação Neuropsicológica e Neurolingüística}

Avaliação Neuropsicológica: Sr. AR obteve escore máximo no teste Mini-Mental (30 pontos) e nas provas do Protocolo de Critério de Positividade para o Déficit Cognitivo, ambos adaptados por Chaves e Isquierdo (1992). No teste de Raven obteve nível superior (percentil $95 \%)$.

Avaliação da Leitura e da Escrita: A compreensão de leitura ficara inalterada apesar da incapacidade em ler em vOz alta. Recusava-se a escrever, pois queria utilizar a mão direita que ficara paralisada. Dias depois, foi realizado um ditado de palavras, onde apareceram algumas inversões de letras, normais numa pessoa que utiliza pela primeira vez a mão esquerda, e omissões de letras em palavras extensas. A família foi orientada a fazer ditados de palavras, aumentando paulatinamente a extensão e a estrutura silábica dos estímulos. Uma semana após, senhor AR não apresentava mais as dificuldades de escrita. Dois meses depois já estava utilizando o computador e se comunicando pela internet, movimentando apenas a mão esquerda.

Compreensão: $O$ paciente foi submetido ao protocolo da avaliação de afasia Montreal-Toulouse-84 (Nespoulous e cols., 1984) um mês e meio após seu problema. A compreensão de palavras e frases em provas de emparelhamento entre a emissão oral do examinador e figuras era normal, assim como a compreensão oral de conversas estava bastante adequada. Nas provas de 
emparelhamento palavra escrita ou frases e figuras, também não apresentou nenhum erro.

Expressão Oral: O paciente foi incapaz de realizar todas as provas da avaliação de afasia Montreal-Toulouse84 (Nespoulous e cols., 1984) que exigiam emissão oral - repetição, leitura em voz alta e nomeação de figuras e objetos - devido sua incapacidade em articular qualquer fonema de forma audível. Sua emissão era sussurrada e os movimentos articulatórios eram mínimos. Entretanto, não apresentava apraxia para outros movimentos bucofaciais, se realizados de forma isolada: sob comando visual ou oral, movimentava adequadamente língua e lábios, mas não conseguia fazer movimentos seqüenciais, como estalar a língua.

\section{Avaliação Fonético-fonológica}

Método: Para avaliação acústica utilizou-se o programa Dr. Speech da Tiger Eletronics versão 3.4. Além do paciente AR, um sujeito do sexo masculino e de mesma idade do paciente realizou as mesmas provas. Os sujeitos emitiram a vogal sustentada/a/ procurando manter o padrão habitual de voz. Posteriormente, repetiram palavras emitidas pelo avaliador, as quais foram previamente selecionadas a partir de um balanceamento

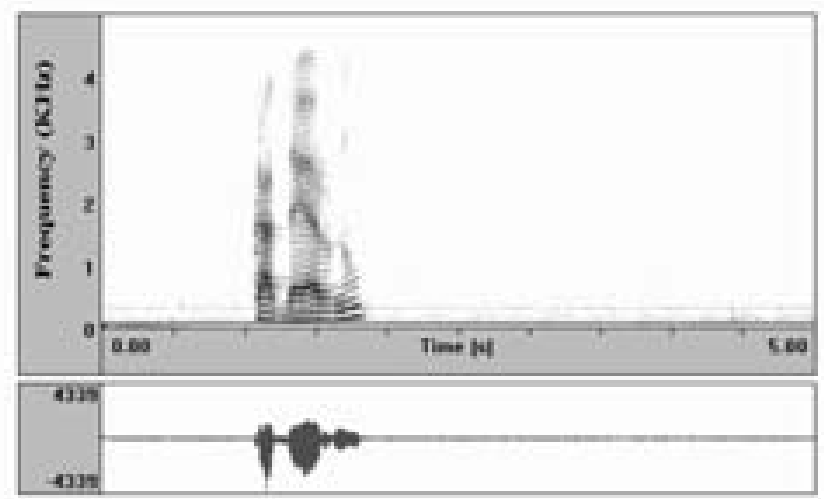

Figura 1a. Uma emissão da palavra caderno pelo sujeito sem anartria. Cada mancha corresponde a uma sílaba da palavra.

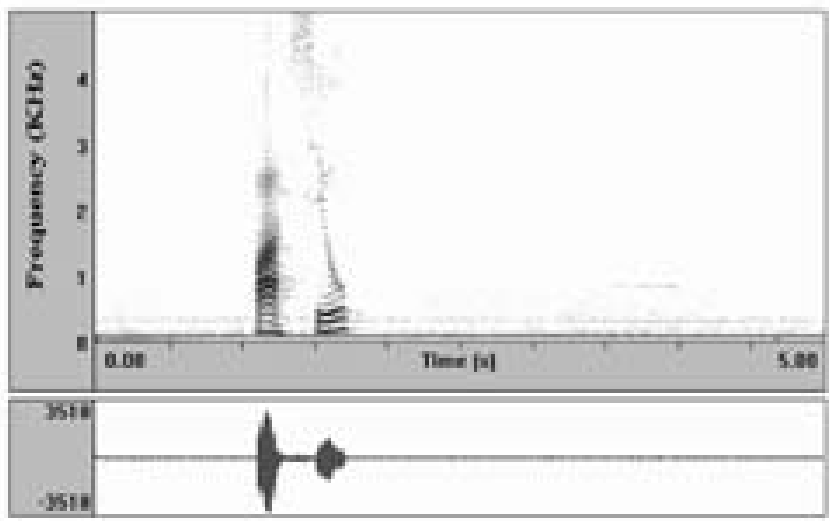

Figura 2a. Emissão da palavra tácil pelo sujeito sem anartria. Cada mancha corresponde a uma sílaba da palavra. fonético. Foi utilizada a distância padrão de 10 centímetros entre o microfone e a boca do sujeito avaliado, para captação do som utilizamos um sampling rate de 22.050 Hz. Após a coleta dos dados, os exames foram analisados e comparados utilizando-se os mesmos critérios de análise.

Resultados: $\mathrm{Na}$ espectrografia do sujeito com anartria verificaram-se várias características quando comparado a emissão do sujeito normal, entre elas, prolongamento dos fonemas surdos e sonoros. Por exemplo, em algumas plosivas ocorreu um aumento no tempo de sonorização e um incremento de energia no ponto de oclusão. Podemos observar, que o tempo de emissão da palavra "caderno" é bem mais curto em um indivíduo normal (Figura 1a) se comparada com a emissão do paciente RA (Figura 1b). É saliente a maior quantidade de tempo necessária para dizer a sílaba "ca". Quanto às fricativas, o prolongamento do fonema /f/ é visível como se demonstrou na produção da palavra "fácil" (Figuras 2a e 2b). Observa-se, no exame do paciente, que a "mancha" da sílaba inicial "fa" é bem mas larga do que a que se observa no exame do indivíduo sem anartria. Já nas consoantes e vogais nasais, ocorreu uma diminuição do componente de nasalização (hiponasalidade).

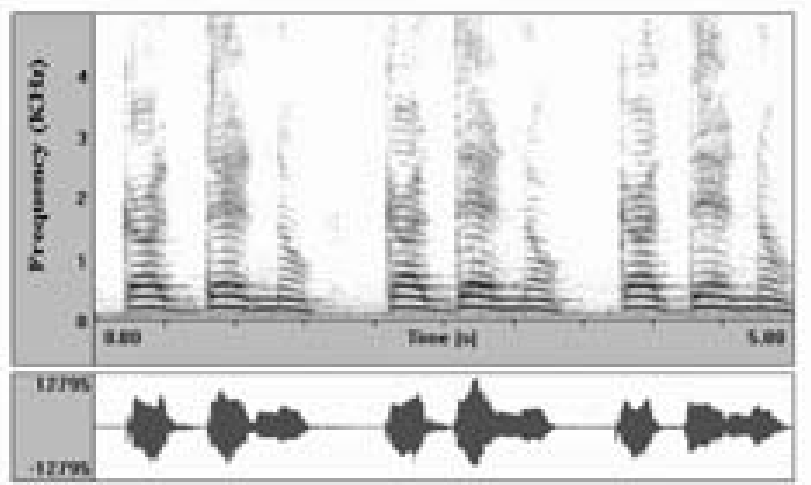

Figura 1b. Três emissões da palavra caderno, realizadas pelo sujeito com anartria. Observe o aumento no tempo de sonorização. Nesse exame, cada agrupamento de manchas mostra uma das emissões do paciente e cada mancha corresnonde a uma sílaba da nalavra.

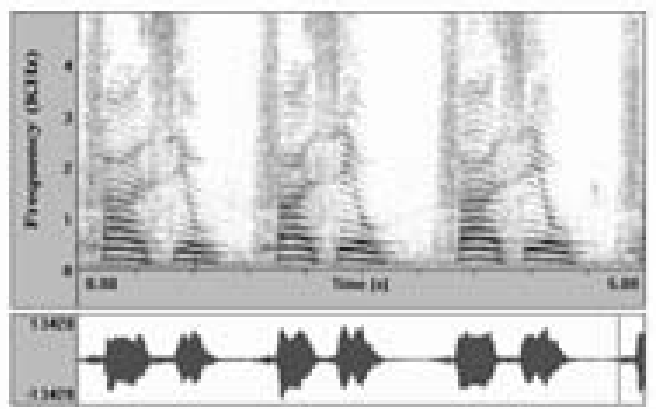

Figura 2b. Três emissões da palavra fácil pelo sujeito com anartria. Observe o prolongamento na emissão do fonema /f/ nas primeiras manchas de cada par de manchas. 
A fala do sujeito acometido pela anartria caracterizouse por lentificação e aumento na duração das sílabas. Cabe ressaltar que apesar de o indivíduo poder sonorizar, houve uma certa inconsistência na duração e qualidade da emissão, assim como, repetição de algumas sílabas e trocas quanto à sonoridade dos fonemas em ambas as direções: surdo - sonoro e sonoro - surdo. Na avaliação perceptivo-auditiva da voz foram observados tempos máximos de fonação reduzidos; qualidade vocal soporosa; loudness fraco; pitch médio, tendendo ao agudo; e ressonância laringo-faringea associada a um foco posterior e a um esforço durante a fonação.

$\mathrm{Na}$ análise acústica da voz na emissão sustentada da vogal /a/, encontrou-se redução de harmônicos, a partir de $2.000 \mathrm{~Hz}$ em banda estreita, e restrição em suas definições. O traçado em banda larga demonstrou aperiodicidade entre os ciclos e presença de ruído nas freqüências altas. $\mathrm{Na}$ prova de diadococinesia laríngea foram emitidas sete sílabas em 3 segundos de emissão.

Estudo Tomográfico: A tomografia realizada no dia seguinte após o EVE detectou um hematoma intraparenquimatoso na região temporo-parietal à esquerda medindo 4,5 X 3,0 cm nos seus maiores diâmetros, acompanhado por um halo de hipodensidade, relacionado a um edema. Um mês depois, a tomografia de controle, mostrava uma diminuição das dimensões do hematoma, mas a manutenção do edema de substância branca adjacente. $\mathrm{O}$ laudo da ressonância magnética, realizada um ano após (20 de setembro de 2000), descrevia: área de hipointensa localizada na região do giro frontal inferior esquerdo e ínsula deste lado, aparentemente poupando ou atingindo muito levemente o córtex cerebral, acompanhando-se de ampliação de alguns sulcos junto ao giro frontal e giro pré-frontal (Figura 3).

Evolução: A evolução da emissão oral foi mais lenta e exigiu um esforço bem grande do paciente. Nos dois

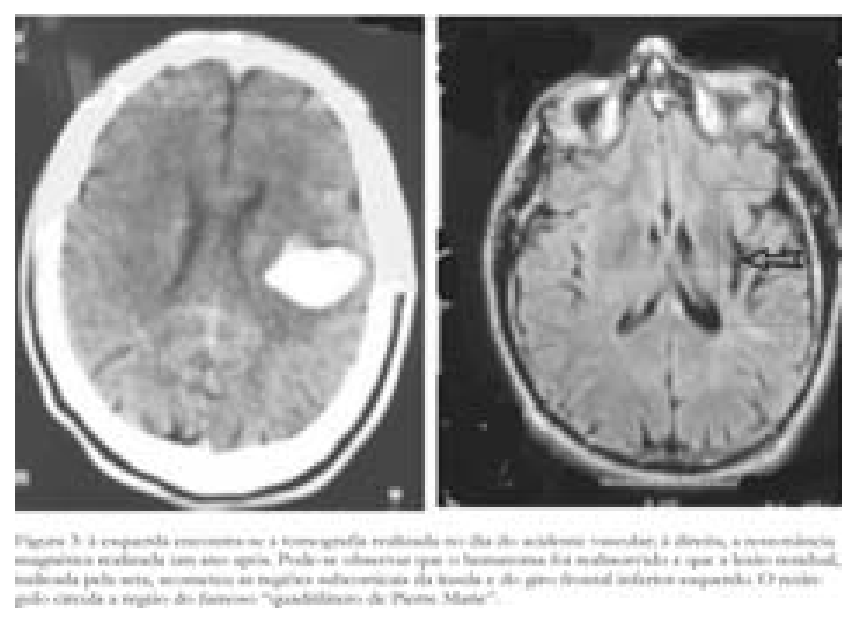

Psicologia: Reflexão e Crítica, 2001, 14(2), pp. 367-377 primeiros meses foi realizado um trabalho de recuperação dos movimentos necessários para cada fonema. Este trabalho contou com o apoio de desenhos das posições dos órgãos fono-articulatório e fonéticos, conforme proposição de Luria (1970) e com a introdução da terapia melódica (Sparks \& Deck, 1986). Inicialmente foram trabalhadas as vogais e suas posições. Depois, lentamente, foram introduzidas, sucessivamente, as consoantes bilabiais, linguodentais, oclusivas posteriores. A seguir, com um trabalho de sopro concomitante, as sibilantes, as labiodentais - que apresentam uma nuance entre o escape de ar e a posição labial - e as laterais, deixando para o fim, a distinção do "R" brando (por exemplo: cara) do "R" posterior (por exemplo: carro). O trabalho de cada fonema iniciou-se com palavras curtas, formadas por sílabas simples. Silabas mais complexas foram trabalhadas posteriormente.

Apesar de articular os fonemas do português, os movimentos eram lentos, gerando uma fala silabada e escandida. Muitas vezes, ao conversar, parava no meio da frase, até mesmo no meio de uma palavra longa, com dificuldades de lembrar o que estava articulando. Referia que seu pensamento era muito mais rápido do que sua possibilidade de falar; precisava sempre prestar atenção entre o que estava pensando e o que estava falando, e isso o cansava muito.

O paciente foi acompanhado por dois anos. Ao final desse período comunicava-se normalmente, apesar da lentidão, o que o impediu, até a época, de voltar a todas funções de seu trabalho. Sua esposa reorganizou sua vida, com atividades de reabilitação, de lazer e trabalho: continuou com trabalho fisioterápico e iniciou atividades esportivas que gostava; em sua firma fazia contatos com alguns clientes, mas precisava do apoio de seu sócio.

\section{Discussão}

Esse estudo apresenta dois pacientes, do sexo masculino, adultos, que devido a um problema de acidente cérebro-vascular apresentavam anartria pura: perderam a capacidade de fala, sem alterações significativas de linguagem oral, leitura e escrita. Ambos não perderam sua consciência no estado agudo e tiveram dificuldades motoras que regrediram nitidamente ao nível dos membros inferiores. $\mathrm{O}$ paciente francês melhorou consideravelmente sua mobilidade dos braços, mas, no paciente brasileiro, a paresia braquial persistiu em movimentos finos de dedos. Esta evolução motora considerável, assim como a ausência de outras dificuldades cognitivas não lingüísticas, são índices de uma lesão cerebral bastante específica, que em ambos pacientes 
manteve intacta a área de Broca, com alterações em suas vizinhanças subcorticais.

Isto pode ser comprovado observando-se a ressonância magnética realizada um ano após o evento hemorrágico no paciente brasileiro. O hematoma foi reabsorvido e a área de hipointensidade, indicativa de lesão residual, estende-se predominantemente nas regiões subcorticais da insula (junto ao putâmen, claustro e cápsula externa) e do giro frontal inferior esquerdo. Esta localização tem clara correspondência com áreas envolvidas em casos de anartria pura, segundo Dejerine (1907) e Marie (1906/1926b e d). Nestes locais, conforme Lecours e Lhermitte (1976), ocorreria lesão das fibras U e um isolamento da área de Broca. $\mathrm{Na}$ fase aguda dos eventos vasculares hemorrágicos, o cérebro adjacente ao hematoma e ao edema cerebral pode ser muito pressionado, mas a área de destruição neuronal propriamente dita costuma ser pequena. A evolução do paciente foi típica de casos de hemorragia cerebral intraparenquimatosa nas quais a restauração da função, ainda que lenta, costuma ser muito melhor que nos infartos. $\mathrm{Na}$ medida em que o edema tecidual reduziu-se e o sangue foi reabsorvido, o efeito de massa sobre a área de Broca desapareceu e o distúrbio de linguagem tornou-se compatível com lesão de dimensões bem menores, restritas ao nível subcortical.

Duas diferenças semiológicas, que ocorreram em apenas dois pacientes, serão inicialmente discutidas: (1) a dissociação entre a pronunciação francesa e inglesa do paciente francês e (2) as falhas iniciais de escrita do segundo paciente. Após, discutiremos três dissociações comuns a ambos: (1) compreensão da linguagem normal e falhas na produção; (2) expressão escrita normal e falhas na expressão oral; e, (3) dificuldades exclusivas na estrutura fonética da linguagem.

Dissociação entre a Língua Inglesa e Francesa: Alajouanine, Pichot e Durant (1949) postularam ter encontrado uma dissociação entre a recuperação das duas línguas, favorecendo o inglês. Com relação à dissociação, e considerando as técnicas e teorias da época na qual Durand realizou seu estudo experimental, gostaríamos de salientar a admiração que suscita seu trabalho pioneiro. Entretanto, diferentemente dos distúrbios de linguagem em bilíngües que podem ser diferentes quanto à conservação ou à evolução de uma das línguas conhecidas pelo paciente, evidenciando representações cerebrais distintas (para uma revisão sobre bilingüismo e afasia, ver Paradis, 1977 e Paradis e Lecours, 1979), não acreditamos que a diferença entre a fala francesa e inglesa no Senhor Delfrique represente uma "dissociação". O mais provável é que um distúrbio da fala, que possui como uma das características salientes à pronúncia de segmentos que evocam ditongos, seja mais perceptível na língua em que esses fonemas são mais freqüentes. Se o paciente francês também tivesse sido um locutor do português, é provável que a desintegração fonética fosse semelhante, tanto na primeira língua como na segunda.

Segundo Alajouanine, Pichot e Durand (1949), a desintegração fonética, mesmo que limitada ao nível fonético da linguagem falada, resulta de uma falha em nível relativamente central do funcionamento humano. Esta opinião parece aceitável. Pode-se observar, freqüentemente, na desintegração fonética isolada, diferenças importantes entre a fala proposicional e a automática (por exemplo, a conversa não emotiva versus a recitação de uma oração). Mesmo assim, é improvável que nesse quadro, as diferenças entre línguas diferentes quanto ao nível fonético possam levar a uma autonomia anatomo-funcional dos locais cerebrais que governam sistemas fonéticos de bilíngües com lesão cerebral.

Falhas Iniciais de Escrita: a segunda diferença entre os dois casos foi a presença de uma disortografia no paciente brasileiro, que regrediu após dois meses de trabalho. Essa recuperação imediata deve-se, provavelmente, à diminuição de edema cerebral, evidenciando que a lesão mais resistente causou um distúrbio de específico na produção da fala. Esta evolução reafirma a opinião de Marie (1906/1926a), de que o quadro anártrico pode, no início da evolução, ser confundido com um quadro de afasia motora, onde ambas modalidades lingüísticas encontram-se afetadas. Portanto, a avaliação neuropsicológica deve considerar modificações clínicas decorrentes da evolução espontânea. Esse fato torna-se bastante relevante, uma vez que a conduta terapêutica difere radicalmente quando há um comprometimento lingüístico de acesso lexical ou semântico, na afasia de Broca (Kohn, Smith \& Alexander, 1996; Micelli, Amitrano, Capasso \& Caramazza, 1996) ou quando se restringe à produção de fala.

Compreensão da Linguagem Normal e Falhas na Produção: Desde o início do problema cerebral, o comportamento dos dois pacientes confirmou a existência da primeira dissociação devido ao bom desempenho nas provas de compreensão lingüística. Essa dissociação também é encontrada nos pacientes afásicosmotores, e, portanto não é uma característica patognomônica da anartria pura.

Expressão Escrita Normal e Falhas na Expressão Oral: Esta segunda dissociação também não é questionada nesses casos. Como já discutimos, a rápida evolução das dificuldades de escrita do senhor AR indica a presença de edema nas áreas adjacentes ao foco da lesão. Já o 
grafismo do senhor Delfrique era aceitável e não havia uma disortografia atribuível à lesão do paciente. Parecenos válido, lembrar a freqüência dos distúrbios de grafismo e de ortografia em quase todas as formas de afasia, incluindo as que, juntamente com outros sintomas, mostram comportamentos de desintegração fonética. De mesma forma, a lentidão do Sr. Delfrique ao escrever é a mesma do que grande número de lesados cerebrais.

\section{Dificuldades Exclusivas na Estrutura Fonética da Linguagem}

Uma terceira dissociação considera falhas seletivas nas diferentes estruturas da linguagem: a morfossintaxe, semântica e fonologia encontram-se intactas, mas não a fonética. (Buyssens, 1967; Lecours, Dordain \& Lhermitte, 1970; Martinet, 1967). Essa dissociação pode ser analisada de duas maneiras. De um lado, era evidente que tanto a estrutura semântica, como a morfossintática, estavam preservadas em atividades lingüísticas complexas, como a narração e a conversa. Entretanto, pode-se questionar se o sistema fonológico encontrava-se também afetado: os dois pacientes produziam, raramente, transformações que não podiam ser diferenciadas das parafasias fonêmicas dos afásicos sem problemas articulatórios, salvo por seu componente puramente fonético (Blumstein, 1973; Lecours \& Caplan, 1975; Lecours \& Lhermitte, 1969; Poncet, Degos, Deloche \& Lecours, 1972). Esta característica correspondia ao que Alajouanine e Lhermitte (1960) definiram como sendo o componente disártico da desintegração fonética. Nessa perspectiva, a dificuldade dos pacientes não é causada por uma desintegração fonológica, mesmo se as parafasias fonêmicas fossem mais freqüentes do que as realizadas normalmente por pessoas sem lesão.

O estudo da fala dos dois pacientes leva-nos a concluir que eles possuíam "anartria pura", com lesão nos circuitos neurais responsáveis pela realização fonética. $\mathrm{O}$ dano cerebral, de localização telencefálica específica não afetou outras funções lingüísticas. $\mathrm{Na}$ escola russa, o quadro denominado afasia motora aferente (Luria, 1964) apresenta sintomas semelhantes à anartria pura: "apraxia posicional dos órgãos da fala e busca de movimentos apropriados para os diferentes sons" (p. 149). Entretanto, Luria considera que a busca dos esquemas motores ocasiona problemas secundários que irão afetar a escrita. Nesse sentido, a afasia motora aferente se diferenciaria da anartria pura. $\mathrm{Na}$ escola neuropsicológica americana, vários autores também não distinguem a chamada "apraxia de fala" da afasia. Darley, Aronson e Brown (1975) descrevem o tratamento de um anártrico com uma afasia associada relativamente grave. Entretanto, a

Psicologia: Reflexão e Crítica, 2001, 14(2), pp. 367-377 presença de uma afasia global inicial pode questionar o diagnóstico de uma "apraxia de fala", devido a um comprometimento lingüístico mais abrangente.

Do ponto de vista nosológico, atualmente, não há um consenso se a anartria deva ou não ser incluída nos quadros afásicos. Em parte, devido ao grande prestígio de Pierre Marie em sua época, a anartria foi excluída do domínio da afasia. Se considerarmos que os distúrbios adquiridos da compreensão e da expressão que afetam a morfosintaxe, a semântica e a fonologia, tanto na linguagem oral como na escrita, são qualificados como afasia, e que a desorganização fonética da terceira articulação é igualmente dita como afásica, se estiver compondo um quadro semiológico complexo (afasia de Broca), não percebemos nenhum motivo - embora este quadro clínico não seja freqüente - para excluir a desintegração fonética pura (ou quase) do conceito de afasia. Se nós fizéssemos isto, outras exclusões seriam necessárias (por exemplo, a afasia de condução com apenas transformações de fonêmicas, durante uma evolução favorável). Assim, concordamos com a posição de Lordat (1843), Baillarger (1890) e Dejerine (1914) e não com a de Marie (1906/1926a, b, c; 1907/1926).

Quanto às características articulatórias da fase distônica da anartria, é preciso considerar que, do ponto de vista da neurolingüística, um fonema é o resultado audível da produção de um conjunto de movimentos articulatórios sincronizados. Esses estados dinâmicos de contrações musculares de diversos níveis são chamados "traços". A observação clínica tem evidenciado que os pacientes variam quanto às dificuldades que apresentam nos diversos fonemas (Fromkin, 1971). Também variam as formas de paresia e distonia, que podem estar ou não presentes. Por exemplo, as formas de nasalização não são tão constantes como nas disartrias de tipo bulbares da doença de Charcot (esclerose lateral amiotrófica). Cabe lembrar ainda que apesar das disartrias telencefálicas produzirem falhas motoras, uma falha proprioceptiva pode ocorrer concomitantemente, o que caracteriza uma apraxia, como assinalava Luria (1964).

Quando Durand estudou o paciente, ele produzia transformações características de distonia (Alajouanine, Pichot \& Durant, 1949). Como o Senhor AR, as transformações mais freqüentes dessas emissões eram resultado de movimentos bucofonotórios com contração muscular exagerada, seguida de uma anomalia na dinâmica do movimento intermediário que correspondia ao traço deformado. A fala lentificada tem sido observada em diversos pacientes com anartria, que levam o dobro do tempo para produzir palavras longas e frases (Lebrun, 1993; Lebrun, Buyssens \& Henneaux, 1973). 
Em termos motores, essa anomalia poder ser explicada devido a: (1) uma incapacidade em realizar uma contração intermediária; (2) um atraso ou uma intermitência na produção, ou ainda, (3) um retorno à mobilidade exagerada. Ocorre um jogo muscular relativamente intenso, necessário para a produção convencional do traço normal; pode-se até mesmo dizer que a emissão oral torna-se exageradamente normal. Por exemplo, durante a fase distônica da desintegração fonética, as oclusivas, as orais e surdas mantém-se inalteradas. Os traços dinâmicos que requerem uma contração de menor intensidade, na produção normal, estão bem mais comprometidos. As fricativas são um exemplo facilmente perceptível: ou elas se transformam, no período inicial, em oclusivas vizinhas ou tornam-se africadas. Ainda que os antagonistas não sejam exatamente os mesmos, a transformação das laterais que solicitam a participação da ponta da língua tem natureza semelhante, tornandoas oclusivas. De mesma forma, a ausência de sonorização dos fonemas sonoros, assim como a intermitência na duração anormalmente curta ou longa da sonorização, sugerem alterações nos músculos laríngeos. Em termos acústicos, tais dificuldades foram visualizadas no espectrograma como: (a) aumento e/ou diminuição do tempo de sonorização; (b) incremento de energia do ponto de oclusão; e, (4) prolongamento das fricativas. No espectrograma da vogal sustentada " $a$ " em banda estreita, a redução dos harmônicos observada, pode também indicar uma dificuldade na fonte glótica, contribuindo para o padrão irregular da sonorização.

A instabilidade na amplitude das vogais observada nos dois casos desse estudo tem sido relatada em outros estudos. Lebrun e colaboradores (1973) observaram que o padrão oscilográfico da fala de um paciente com anartria evidenciava a presença de vogais com constituição normal numa etapa inicial, mas com pequenas ondas de amplitude diminuída, numa etapa posterior. Para a audição, este final anormal da vogal é percebido como um golpe de glote.

De forma semelhante à das africadas, a produção dos pseudoditongos e dos pseudopolitongos testemunha uma dificuldade de atingir ou manter um nível apropriado de contração do lado dos músculos responsáveis pelo grau de abertura bucal. Esta explicação também é válida para os fenômenos de epênteses ou de oclusão preliminar de uma vogal inicial. Portanto, o mesmo pode ocorrer nos músculos labiais, linguais velares e laríngeos. De fato, vários traços de um mesmo fonema podem estar comprometidos em concomitância.

Quanto às áreas responsáveis pela desintegração fonética pura, já mencionamos que tanto Pierre Marie (1907/1926) e Dejerine (1914) eram de opinião que a lesão sempre era subcortical na desintegração motora pura (região subcortical da área de Broca com desconexão do opérculo Rolandico) ou na "anartria pura" (zona lenticulada). A hipótese de um isolamento funcional da área de Broca por referência ao córtex motor primário continua sendo um postulado razoável, mas não necessariamente absoluto. Uma lesão que isola a área de Broca das circunvoluções frontais ascendentes esquerdas e direita pode comprometer tanto a córtex como a subcórtex. Assim, as lesões limitadas à córtex de uma determinada área, ou seja, deixando intactas as fibras em «U», são raríssimas ou inexistentes nas isquemias e em outras doenças de origem abrupta. Do ponto de vista prático, pode-se evocar duas possibilidades: (1) há lesões corticais e subcorticais que ocasionam uma afasia de Broca com anartria e (2) existem lesões subcorticais que produzem uma "síndrome de desintegração fonética pura" ou a "anartria pura". Desta forma, uma falha exclusiva da terceira articulação da fala pode emergir de um distúrbio mais complexo. Entretanto, lesões cujo local é específico podem, em teoria, afetar a apenas a programação fonoarticulatória oriunda da área de Broca e que utiliza outras estruturas do hemisfério esquerdo. Isto é ilustrado por esses dois pacientes, portadores de lesão córtico-subcortical limitada à circunvolução frontal ascendente. Pode-se considerar também a presença de lesões subcorticais que desconectam esta última e a área de Broca, como por exemplo, uma lesão na parte anterior da cápsula interna.

Finalmente, ainda não temos uma hipótese sobre o impacto potencial das lesões insulares na desintegração fonética. É verdade que lobo límbico influencia a fala, mas sua influência no nível fonético parece-nos mais reduzida, apesar de algumas "ilhas de fluência" e da maior facilidade em emitir expressões automáticas e de caráter afetivo.

\section{Referências}

Alajouanine T., Ombredane A. \& Durand M. (1939). Le syndrome de désintégration phonétique dans l'aphasie. Paris: Masson.

Alajouanine T., Pichot P. \& Durand M. (1949). Dissociation des altérations phonétiques avec conservation relative de la langue la plus ancienne dans un cas d'anarthrie pure chez un sujet français bilingue. Encéphale, $28,245-265$.

Alajouanine T. \& Lhermitte F. (1960). Les troubles des activités expressives du langage dans l'aphasie. Revue Neurologique, 102, 66-91, 1960.

Baillarger J. G. F. (1890). De l'aphasie du point de vue psychologique. Aphasie simple. Aphasie avec préservation de la faculté du langage. Em J.G.F. Baillarger (Org.), Recherches sur les maladies mentales. Vol I. Paris: Masson. (Original publicado em 1865)

Blumstein, S. E. (1973). A phonological investigation of aphasic speech. Haye: Mouton.

Broca, P. (1861). Remarques sur la siège de la faculté du langage articulé. Bulletin de la Société d'Anthropologie, 2, 330-357.

Buyssens, E. (1967). La communication et l'articulation linguistique. Paris: PUF. Charcot, J. M. (1883). Differenti forme d'afasia. Milão: Antica Casa Editrice Dottor Francesco Vallardi. 
Chaves, M. L. \& Izquierdo, Y. (1992). Differential diagnosis between dementia and depression: a study of efficiency increment. Acta Neurologica Scandinavia, 85, 378-382.

Darley, F. L., Aronson, A. E. \& Brown, J. R. (1975). Motor speech disorders. Philadelphia: Saunders.

Dejerine, J. J. (1907). L'aphasie motrice: sa localisation et son anatomie pathologique. Presse Médicale, 14, 453-457.

Dejerine, J. J. (1914). Sémiologie des affections du système nerveux. Paris: Masson.

Dejerine, J. J. \& Dejerine-Klumpke, A. (1901). Anatomie des centres nerveux. Paris: Rueff.

Freud, S. (1953). On aphasia: A critical study. New York: International Universities Press. (Original publicado em 1891)

Fromkin, V. A. (1971). The non-anomalous nature of anomalous utterances. Language, 47, 27-52.

Jackson, J. H. (1931). On the anatomical and physiological localization of movements in the brain. Em J. Taylor (Org.), Selected writings of John Hugblings Jackson (Vol 1, pp. 45-72). Londres: Hodder and Stoughton. (Original publicado em 1873)

Jakobson, R. (1973). Lingüística e comunicação (I. Blikstein \& J. P. Paes, Trads.). São Paulo: Cultrix (Original publicado em 1953)

Kohn, S. E., Smith, K. L. \& Alexander, M. P. (1996). Differential recovery from impairment to the phonological lexicon. Brain and Language, 52,129-149.

Lebrun, Y., Buyssens, E. \& Henneaux, J. (1973). Phonetic aspects of anarthria. Cortex, 9, 126-135.

Lebrun, Y. (1993). Tratado de afasia. São Paulo: Panamed.

Lecours, A. R. \& Caplan, D. (1975). Blumstein's phonological investigation of aphasic speech. Brain and Language, 2, 237-254.

Lecours, A. R., Dordain, G. \& Lhermitte, F. (1970). Recherches sur le langage des aphasiques. 1. Terminologie neurolinguistique. L'Encéphale, 59, 520-546.

Lecours, A.R. \& Lhermitte, F. (1969). Phonemic paraphasias; linguistics structures and tentative hypotheses. Cortex, 5, 193-228.

Lecours, A. R. \& Lhermitte F. (1976). The "pure form" of the phonetic desintegration syndrome (pure anarthria); anatomoclinical report of a historical case. Brain and Language, 3, 88-113.

Lecours, A. R. \& Lhermitte, F. (1979). L'aphasie. Paris: Flammarion.

Lordat, J. (1843). Analyse de la parole pour servir à la théorie de divers cas d'alalie et de paralalie (de mutisme et d'imperfection du parler) que les nosologistes ont mal connus. Journal de la Société de Médecine Pratique de Montpellier, 7, 333-353.

Luria, A.R. (1964). Factors and forms of aphasia. Em A.V.S. de Reuck \& M. O'Connor (Orgs.), Disorders of language (pp. 143-167). London: J. \& A. Churchill.
Luria, A. R. (1970). Traumatic aphasia. Haye: Mouton.

Marie, P. (1926a). La troisième circonvolution frontale gauche ne joue aucun rôle spécial dans la fonction du langage. Em P. Marie (Org.), Travaux et mémoires (Tomo I, pp. 3-30). Paris: Masson. (Original publicado em 1906)

Marie, P. (1926b). Que faut-il penser des aphasies sous-corticales (aphasies pures)?. Em P. Marie (Org.), Travaux et mémoires (Tomo I, pp. 31-43). Paris: Masson. (Original publicado em 1906)

Marie, P. (1926c). L'aphasie de 1861 a 1866. Essai de critique historique sur la genèse de la doctrine de Broca. Em P. Marie (Org.), Travaux et mémoires (Tome I, pp. 44-65). Paris: Masson. (Original publicado em 1906)

Marie, P. (1926d). Un cas d'anarthrie transitoire par lésion de la zone lenticulaire. Em P. Marie (Org.), Travaux et mémoires (Tome I, pp. 6682). Paris: Masson. (Original publicado em 1906)

Marie, P. (1926). Sur la fonction du langage. Em P. Marie (Org.), Travaux et mémoires (Tome I, pp. 83-94). Paris: Masson. (Original publicado em 1907)

Martinet, A. (1967). Éléments de linguistique générale. Paris: Collin.

Micelli, G., Amitrano, A., Capasso, R. \& Caramazza, A. (1996). The treatment of anomia resulting from output lexical damage: Analysis of two cases. Brain and Language, 52, 150-174.

Nespoulous, J-L., Lecours, A. R., Lafond, D., Lemay, A., Joanette, Y., Cot, F., Rascol, A. \& Parente, M. A. M. P. (1986). Protocolo Montreal-Toulouse de exame lingüistico de afasia MT-86. Montreal: Laboratoire ThéophileAlajouanine.

Paradis, M. (1977). Bilinguism and aphasia. Em H. Whitaker \& H.A. Whitaker (Orgs.) Studies in neurolinguistics (Vol.3, pp. 65-78). New York: Academic Press.

Paradis, M. \& Lecours, A. R. (1979). L'aphasie chez les bilingues et les polyglotes. Em A.R. Lecours \& F. Lhermitte L'aphasie (Orgs.), L'aphasie (pp. 605-616). Paris: Flammarion.

Poncet, M., Degos, C., Deloche, G. \& Lecours, A.R. (1972). Phonetic and phonemic transformations in aphasia. International Journal of Mental Health, 1, 46-54.

Saussure, F. de (1955). Cours de linguistique générale (5a edição). Paris: Payot. (Original publicado em 1916)

Sparks, R. W. \& Deck, J. W. (1986). Melodic intonation therapy. Em R. Chapey (Org.), Language intervention strategies in adult aphasia ( $2^{\mathrm{a}}$ ed., pp. 245-287). Baltimore: Williams \& Wilkins.

Recebido: 22/11/2000

Revisado: 22/3/2001

Aceite final: 8/4/2001

Sobre os autores:

André Roch Lecours, é Professor do Departamento de Geriatria e Gerontologia da Universidade de Montreal, Canadá. Fundador do Laboratório Theophile Alajouanine no Centro de Pesquisas do Centro Hospitalar Côte-des-Neiges, Universidade de Montreal, Canadá. Fundador da Sociedade Latino Americana de Neuropsicologia.

Maria Alice de Mattos Pimenta Parente é Doutora em Psicologia pela Universidade de São Paulo, Membro da Assembléia de Pesquisadores do Centro de Pesquisas do Centro Hospitalar Côte-desNeiges da Universidade de Montreal, Canadá. Professora do Departamento de Psicologia do Desenvolvimento e da Personalidade da Universidade Federal do Rio Grande do Sul, Membro da Junta diretora da Sociedade Latino Americana de Neuropsicologia.

Adriana Vélez Feijó é Fonoaudióloga, Mestre em Clinica Médica da Universidade Federal do Rio Grande do Sul.

Alberto Maia é Neurologista, Mestre em Clínica Médica da Universidade Federal do Rio Grande do Sul. Ambulatório de Neuromemória do Hospital de Clínicas de Porto Alegre 


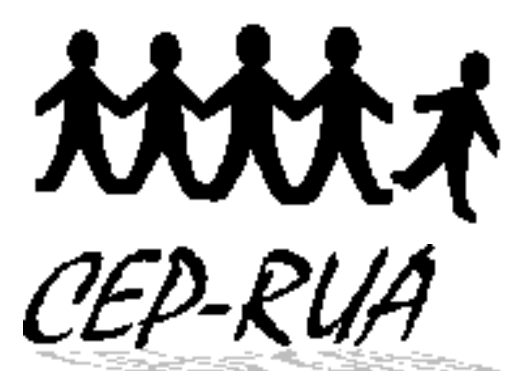

Fundado em 1994
Centro de

Brstudos

Psicológicos

sabre

Meninos e

Meninas de Rua

reúne os psicólogos Sílvia H. Koller, Alessandra Marques Cecconello, Carolina Lisboa, Clarissa De Antoni, Cláudio S. Hutz, Denise R. Bandeira, Gabriela Azen Azevedo, Juliana Prates Santana, Letícia Forster, Lísia Ramos Mayer, Lucas Neiva Silva, Paola Biasoli Alves, alunos de Graduação e Pós-Graduação. Os objetivos principais do CEP-RUA são: ensino, extensão e pesquisa sobre aspectos psicológicos de crianças, adolescentes e famílias em situação de risco pessoal e social, sob o enfoque da Abordagem Ecológica do Desenvolvimento Humano.

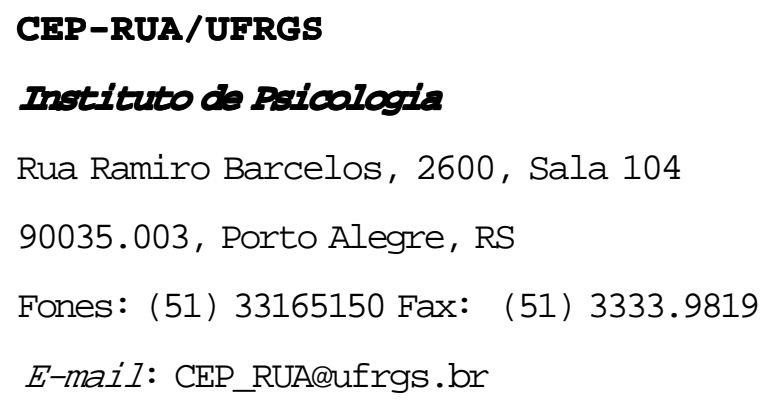

